\title{
Desperate Measures: Shunt Insertion under Local Anesthesia
}

\section{Sir,}

Neurological compromise, when added to complex cyanotic heart disease (CHD), poses a challenge for both surgeon and anesthesiologist. General anesthesia (GA) in such cases comes with inherent risks of compromised hemodynamic parameters and chances of prolonged recovery from anesthesia requiring postoperative mechanical ventilation and related complications. Regional anesthesia with sedation has already been successfully tried in awake craniotomy, carotid endarterectomy, and evacuation of chronic subdural hematoma in neurosurgery. ${ }^{[1,2]}$ We present successful ventriculoperitoneal shunt insertion in a case of complex cyanotic congenital heart disease under local anesthetic (LA) infiltration and dexmedetomidine infusion.

A 16-year-old girl, a known case of uncorrected complex congenital CHD with multiple cerebral arteriovenous malformations, presented with raised intracranial pressure (ICP). On echocardiography, there was a common atrium, common atrioventricular valve, balanced D-looped ventricles, double outlet right ventricle, severe infundibular pulmonary stenosis (pressure gradient of $70 \mathrm{mmHg}$ ), confluent branch pulmonary artery stenosis, bilateral superior vena cava to respective atria, and the absence of coronary sinus. The patient was drowsy but responding to commands with a Glasgow Coma Scale of 12 (E3V4M5). On room air, patient's oxygen saturation was $70 \%$ while baseline heart rate and blood pressure (BP) were $76 / \mathrm{min}$ and $96 / 62 \mathrm{mmHg}$, respectively, with arterial blood gas (ABG) analysis suggestive of compensated metabolic acidosis. In view of raised ICP secondary to hydrocephalus, emergency ventriculoperitoneal shunt (VPS) insertion was planned. Patient's parents did not consent for GA and postoperative mechanical ventilation. Thus, the surgery was planned under LA and monitored anesthesia care (MAC) with explained risks.

Patient's radial artery was cannulated under LA for monitoring beat-to-beat arterial pressure and intermittent ABG sampling. Oxygen was supplemented with the nasal cannula at a flow of $4 \mathrm{~L} / \mathrm{min}$, and vital parameters were continuously monitored. Fentanyl $(1 \mu \mathrm{g} / \mathrm{kg})$ was intravenously infused followed by dexmedetomidine at a rate $0.2-0.7 \mu \mathrm{g} / \mathrm{kg} / \mathrm{h}$ to achieve a target Ramsay Sedation Scale-3 (RSS-3) (drowsy but responds to commands). LA infiltration of the surgical site was done with combination of $15 \mathrm{ml}$ of lignocaine $1 \%$ (with adrenaline $1: 200,000)$ and $15 \mathrm{ml}$ of bupivacaine $(0.25 \%)$ with a 23 -gauge needle. A 25 -gauge spinal needle was used to infiltrate the LA agent along the track of subcutaneous tunneling up to right subcostal area, slowly in a manner "infiltrate as you go." Intraoperative period (40 min) was uneventful. The patient was comfortable, tranquil, drowsy and responding to verbal commands (modified RSS-3), and remained hemodynamically stable. Postoperative period was uneventful.

In patients with complex cardiac anomalies, there may be a precipitous fall of BP during induction of 
anesthesia due to significant decrease in systemic vascular resistance (SVR). The patient is also exposed to significant hemodynamic alterations to laryngoscopy and intubation leading to hypertension, dysrhythmia, and increased ICP. High dose of opioid is required to obtund these hypertensive responses which delay the emergence from anesthesia and may require postoperative mechanical ventilation. Hypovolemia and hypotension worsen the existing right to left shunt and cyanosis. Among the anesthetic agents for induction of anesthesia, ketamine has shown the best results in the patients with CHD as it prevents significant decrease in SVR but needs to be avoided in the patients with raised ICP. ${ }^{[1,2]}$ Dexmedetomidine is a highly selective a2-agonist having sedative, anxiolytic, and analgesic effects without causing any respiratory depression. It also has an opioid-sparing effect. This drug has been found to be useful in the management of cyanotic spells at an infusion rate of $0.2 \mu \mathrm{g} / \mathrm{kg} / \mathrm{h}^{[3,4]}$

The success of the infiltration technique depends on the specific drug and adequate dosage. The principle concerns with the LA infiltration are the systemic toxicity of LA agents. The toxic dose of lignocaine with adrenaline is $>7 \mathrm{mg} / \mathrm{kg}$, while for bupivacaine, it is $>2 \mathrm{mg} / \mathrm{kg}$. In this patient, we combined both the LA drugs to reduce the dose of the individual drug and to have early onset of action (lignocaine) and prolonged duration (bupivacaine) of the drug combination..$^{[3-5]}$ Subcutaneous tunneling is the major noxious stimulus which can be adequately controlled with LA infiltration along with intravenous infusion of dexmedetomidine.

We do not recommend shunt insertion under LA and MAC in routine setting, but this can be used in uncommon circumstances when other methods are contraindicated. This is again a measure which can be considered in settings with limited resources but emergent conditions.

\section{Financial support and sponsorship}

Nil.

\section{Conflicts of interest}

There are no conflicts of interest.
Sonia Kapil, Manjul Tripathi ${ }^{1}$, Nidhi Panda, Kanchan K. Mukherjee ${ }^{l}$, Sivashanmugam Dhandapani ${ }^{I}$

Departments of Neuroanaesthesia and 'Neurosurgery, Postgraduate Institute of Medical Education and Research,

Chandigarh, India

Address for correspondence: Dr. Kanchan K. Mukherjee, Department of Neurosurgery, Postgraduate Institute of Medical Education and Research, Chandigarh - 160 012, India. E-mail: kk_mukherjee@hotmail.com

\section{REFERENCES}

1. Baum VC, Barton DM, Gutgesell HP. Influence of congenital heart disease on mortality after noncardiac surgery in hospitalized children. Pediatrics 2000;105:332-5.

2. Menghraj SJ. Anaesthetic considerations in children with congenital heart disease undergoing non-cardiac surgery. Indian J Anaesth 2012;56:491-5.

3. Osborn I, Sebeo J. "Scalp block" during craniotomy: A classic technique revisited. J Neurosurg Anesthesiol 2010;22:187-94.

4. Surve RM, Bansal S, Reddy M, Philip M. Use of dexmedetomidine along with local infiltration versus general anesthesia for burr hole and evacuation of chronic subdural hematoma (CSDH). J Neurosurg Anesthesiol 2016. DOI: 10.1097/ANA.0000000000000305. [Epub ahead of print].

5. Sethi S, Kapil S. Scalp block for brain abscess drainage in a patient with uncorrected tetralogy of Fallot. World J Clin Cases 2014;2:934-7.

This is an open access article distributed under the terms of the Creative Commons Attribution-NonCommercial-ShareAlike 3.0 License, which allows others to remix, tweak, and build upon the work non-commercially, as long as the author is credited and the new creations are licensed under the identical terms.

\begin{tabular}{|l|l|}
\hline \multicolumn{2}{|c|}{ Access this article online } \\
\hline Quick Response Code: & Website: \\
\hline & \\
\hline
\end{tabular}

How to cite this article: Kapil S, Tripathi M, Panda N, Mukherjee KK, Dhandapani S. Desperate measures: Shunt insertion under local anesthesia. J Neurosci Rural Pract 2017;8:S153-4.

(c) 2017 Journal of Neurosciences in Rural Practice | Published by Wolters Kluwer - Medknow 